\title{
Ethanol Extract of Purple Sweet Potato Tubers (Ipomoea batatas L) Decreases Blood Glucose and Increase Total Antioxidant Level in Rats with High Glucose Intake
}

\author{
I Wayan Putu Sutirta Yasa ${ }^{1}$, I Made Jawi ${ }^{2}$ and Agung Nova Mahendra ${ }^{2}$ \\ 1. Clinical Pathology Department, Udayana University, Indonesia \\ 2. Pharmacology Department of Medical School, Udayana University, Indonesia
}

\begin{abstract}
High blood glucose level can increase the production of free radicals and the AGEs. Flavonoids from fruits and vegetables can prevent that events because they have antioxidant and hypoglycemic effects. The aim of this study was to examine possible hypoglycemic and antioxidant effect of the ethanol extract of purple sweet potato tubers. Subject of this study were 20 male adult rats divided into 4 groups with randomized pre-test and post-test control group design. Before treatment, blood samples were collected from retro-orbital sinus of all rats for blood glucose, MDA and total antioxidant measurement as pre-test data. After pre-test, group 1 (control group) rats were given normal diet without ethanol extract of purple sweet potato tubers. Group 2, 3, and 4 rats were given normal diet and ethanol extract of purple sweet potato tubers 1 cc/day, 2 cc/day, 4 cc/day, respectively, for one week. After one week of treatment, treatment groups were given single dose of high glucose intake. Over 1, 2, and 3 hours of treatment with high glucose, the blood samples were collected for post-test examination. The data were then analysed by one way anova and paired-t test, and the result showed a significant increase of blood glucose and MDA in group $1(\mathrm{p}<0,01)$, significant decrease of total antioxidant in group 1 ( $\mathrm{p}<0.01$ ). In group 3 , all of the parameters were different with group 1 and group $2(\mathrm{p}<0.01)$. In group 4, MDA decreased significantly after treatment and the total antioxidant was increased significantly $(\mathrm{p}<0.01)$. From these findings, it can be concluded that ethanol extract of purple sweet potato tubers can maintain the blood glucose level within normal limit, prevent the increase of MDA, and increase total antioxidant of the blood after high glucose intake in rats. The effective dose of the extract in this research was medium dose.
\end{abstract}

Key words: Purple sweet potato tubers, blood glucose, total antioxidant, rat.

\section{Introduction}

Diabetes mellitus (DM) is one of the health problems faced by all the countries in the world, including Indonesia. Common agents used in the therapy of DM includes insulin and oral anti-diabetics (OAD) [1]. Sulfonylurea (one of the many kinds of OAD) increases the secretion of insulin, but can also cause adverse effects to diabetic patients. There is common failure in the administration of sulfonylurea to maintain the blood glucose level within normal limit, because this agent can only stimulate insulin

Corresponding author: I Wayan Putu Sutirta Yasa, M.Si, research fields: Clinical Pathology. E-mail: psutirtayasa@yahoo.com. secretion in a relatively same amount [2], hence it contributes to body weight increase on the patients [3]. The use of alternative agent is needed to overcome this problem in the management of DM. Studies showed that daily dietary pattern and food composition affect the occurrence of DM. Fruits and vegetables high in polyphenol/flavonoid was proved to influence the blood glucose level via pancreatic beta cells insulin production stimulation[3], and could decrease the insulin resistance [2]. Tsuda which is quoted by Ghosh (2007), found that food high in flavonoid, such as purple corn (containing cyanidin 3-glicoside) could prevent the genesis of insulin resistance caused by high fat intake in mice [2]. Dietary pattern also contribute to postprandial blood 

Increase Total Antioxidant Level in Rats with High Glucose Intake

glucose level in diabetic patients. Increase in postprandial blood glucose level is highly associated to the oxidative stress, which is showed by the increase of MDA (malondialdehyde) in the blood, and this can increase the risk of cardiovascular complications. Oxidative stress can be decreased by the administration of antioxidant or foods high in flavonoids [2, 4-7]. In uncontrolled DM, postprandial blood glucose level commonly increased, hence it also increase the risk of cardiovascular complications.

Anthocyanin-rich foods can control blood glucose level and decrease free radicals in streptozotocin-induced diabetic rats [8]. Beside its antioxidant effects, anthocyanin also has hypoglycemic effects in some researches [2], and in vitro, some kinds of anthocyanin can increase the insulin secretion by beta cell of the pancreas [3].

Purple sweet potato tubers from Bali are high in anthocyanin [9], and has antioxidant effects on blood and various organs of mice suffering from oxidative stress [10]. Purple sweet potato tubers has been developed as food product, so it effects should be studied, especially its potentials on controlling postprandial blood glucose and oxidative stress in diabetic patients. To prove its effects, research was done on rats that were given ethanol extract of purple sweet potato tubers and oral glucose load, and then blood samples were obtained to measure the level of blood glucose every hour, total antioxidant, and MDA.

\section{Materials and Methods}

This research is a laboratory experimental research with randomized control group pre and post-test design. The research is done in 1 month in the Animal Laboratory Unit of Pharmacology Department, Medical School, Udayana University. The population of this research was male wistar rats, 3-4 months old, weighing 200-225 gram. The sample size was 20 rats (determined from Fiderer's equation) and were grouped into 4 groups (5 rats in each group). Before the research was done, all rats were treated so for 2 weeks to make them adapted to the laboratory setting. After 2 weeks, blood samples were obtained to measure the level of MDA, total antioxidant, and fasting blood glucose as pre-test data. Then, Group 1 rats were treated as control group as they were given high oral glucose load only. The other groups (group 2, 3 , and 4) were given 1cc, 2cc and 4 cc ethanol extract of purple sweet potato tubers, respectively, on a daily basis for 1 week. The extracts were given orally via sonde. Group 2, 3, and 4 were then treated with high oral glucose load. The control group was treated with water via sonde to adjust for the stress level faced by the treatment groups.

Ethanol extracts of purple sweet potato tubers were made through special procedure. Harvested purple sweet potato tubers were soaked in clean water and peeled. The purple sweet potato tubers then cut cross-sectionally (2-2.5 cm wide) and made into powder. Ethanol (70\%) then added to this powder $(1 \mathrm{~L}$ of ethanol for $1 \mathrm{~kg}$ of tubers). This mixture was filtrated by using three layers of fine cloth. The filtrate was evaporated to get viscous extract. This extract then dissolved again in 1 liter of water, and heated until boiling. The anthocyanin content of the end product was $119 \mathrm{mg} / \mathrm{mL}$.

After 1 week of treatment, all of the rats were given $50 \%$ glucose orally with the dose of $2 \mathrm{~g} / \mathrm{rat}$. The blood samples were then collected in the 30th, 60th, 120th and 180th minute to measure the level of blood glucose, MDA, and total antioxidant. Glucotest, TBARS, and spectrophotometer were used to measure the level of blood glucose, MDA, and total antioxidant level, respectively. The data were then analyzed by $\mathrm{T}$ test and Anova.

\section{Results}

Study results showing pre-test and post-test average level of blood glucose, MDA, and total antioxidant, in all of the trial animal groups can be seen in and Figs. 1-3. 

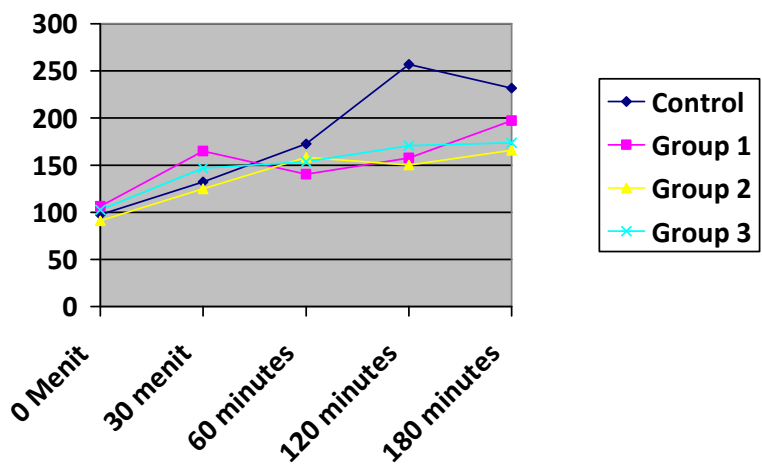

Fig. 1 The comparison of average blood glucose level in all trial animal groups.

The blood glucose level in the initial phase of this study was not significantly different in all of the treatment groups $(\mathrm{p}>0.01)$. In the end of the study (after 3 hours), there was significant blood glucose level increase $(\mathrm{p}<0.01)$, in the control group. In group 3 and 4, the blood glucose level increase was significantly lower than group 1 ( $\mathrm{p}<0.01$ ), meanwhile in group 2 the blood glucose level did not differ significantly compared to group 1 ( $p>0.01$ ). The most intersting thing was the blood glucose level 2 hours of observation. All of the treated grous showed statistically significant lower blood glucose level increase $(\mathrm{p}<0.01)$. All of the treatment groups showed statistically significant lower blood glucose level relative to blood glucose level of the control group ( $\mathrm{p}<0.01)$. Only group 2 showed statistically different result compared to the control group ( $\mathrm{p}<$ 0.01). Fig. 1 shows that there was blood glucose level change during observation. Blood glucose level was higher in control group compared to that of control group from 60th to 180th minute.

Pre-test MDA level in all of the rats in relatively same ( $p$ > 0.01). MDA level was increased one hour after the administration of high glucose intake, and the level was still high until three hours. This increase was statistically significant $(p<0.01)$. Increase in MDA level was also observed in group 2 rats (treated with $1 \mathrm{cc} /$ day extract), which was significantly differ with pre-test MDA level $(\mathrm{p}<0.01)$. If compared with control group, this MDA increase was significantly lower ( $\mathrm{p}<0.01)$.

In group 3 (treated with $2 \mathrm{cc} /$ day extract), MDA level did not change if compared with pre-test MDA level ( $p>0.01)$. MDA level in group 4 showed significant decrease in 3 hours of observation $(\mathrm{p}<$ 0.01). The change in MDA level during 3 hours of observation can be seen in Fig. 2.

Total antioxidant level in the control group rats was significantly decreased after the administration of high glucose intake ( $\mathrm{p}<0.01)$. Meanwhile, in the treatment groups (which were treated with the ethanol extract of purple sweet potato tubers) the total antioxidant level change was dose-dependent. Total antioxidant level decrease was relatively same between group 2 rats (treated with $1 \mathrm{cc} /$ day dose) and group 1 rats (control group). Total antioxidant level did not change in group 3 rats (treated with $2 \mathrm{cc} /$ day dose) $(\mathrm{p}>0.01)$.

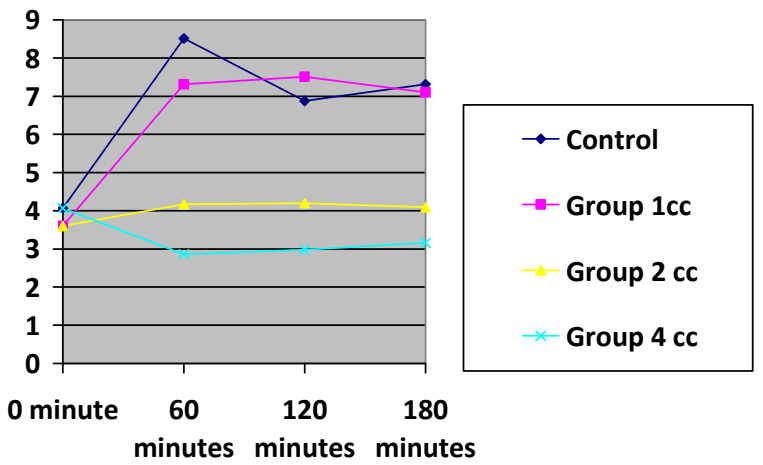

Fig. 2 The comparison of average MDA level in the blood of all of the treatment groups.

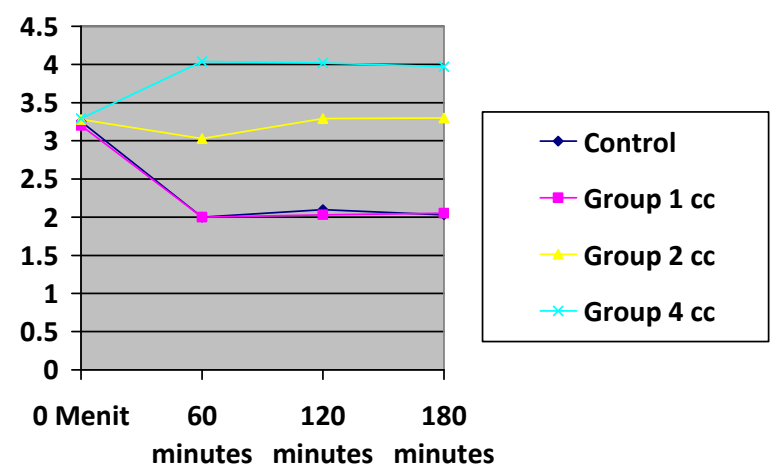

Fig. 3 The comparison of average total antioxidant level in the blood of all of the treatment groups. 
Significant increase in total antioxidant level was observed in group 4 rats (treated with $4 \mathrm{cc} /$ day dose) if compared with pre-test data and the other groups $(\mathrm{p}<$ 0.01). This data can also be seen in Fig. 3.

\section{Discussion}

There were two important things in this study. First, there was significant change in blood glucose level in rats with high oral glucose load, which could be treated by the administration of various doses of ethanol extract of purple sweet potato tubers. Second, there was significant change in blood MDA and total antioxidant level the after high oral glucose load. The blood MDA increase and total antioxidant decrease could also be treated by the administration of the extract. Significant blood glucose level was observed due to high oral glucose load. Compared to pre-test data, the increase differ significantly ( $p<0.01)$, in group 1 . In the treatment groups, which were given ethanol extracts of purple sweet potato tubers for 2 weeks, the blood glucose level increased before high oral glucose load. This increase was observed to be significantly lower than in control group. The difference was significant, in the 60th and 180th minute $(\mathrm{p}>0.01)$. Anthocyanin is a member of flavonoids that is contained within the flesh of purple sweet potato tubers [11]. This agent inhibits glucose absorption through the gastrointestinal tract via the inhibition of alpha-glucosidase, hence anthocyanin has hypoglycemic effect [12, 13]. Anthocyanin also inhibits glucose absorption via various mechanisms [13].

MDA level increase was a marker of oxidative stress [14], in rats given high oral glucose load. Total antioxidant level was also decreased in these rats. In the treatment groups, the level of blood MDA and total antioxidant increased significantly despite being given extract with the dose of $1 \mathrm{cc} /$ day, if compared to the control group and before treatment. The administration of the anthocyanin-rich extract [9], will function as exogenous antioxidant, hence it can increase the total antioxidant level. Anthocyanin is a natural pigment with phenolic structure [15, 16], so that this molecule can transfer hydrogen atom from hydroxyl free radical. The bluish colour of plants is an indicator of high anthocyanin content [17], such as in purple sweet potato tubers. This is the rationale of giving purple sweet potato to increase the total antioxidant level in oral glucose-induced hyperglycemic rats. This effect is certainly due to antioxidant property of the extract, which decrease the use of endogenous antioxidant during oxidative stress. The antioxidant effect of purple sweet potato tubers was proved via DPPH method [11].

The effective dose in this research was 2cc/rat/day. This dose could prevent blood sugar level increase, MDA level increase, and total antioxidant level decrease.

\section{Conclusions}

From this study, it can be concluded that:

(1) The administration of ethanol extract of purple sweet potato tubers can prevent the increase of blood sugar level in rats with high oral intake of glucose.

(2) Ethanol extract of purple sweet potato tubers can decrease blood MDA and increase blood total antioxidant level in rats with high oral intake of glucose.

(3) The effective dose of the ethanol extract of purple sweet potato tubers to prevent blood glucose level increase is moderate dose ( $2 \mathrm{cc} / \mathrm{rat} / \mathrm{day})$.

(4) The effective dose of the ethanol extract of purple sweet potato tubers to prevent the increase of blood MDA and the decrease of blood total antioxidant level is moderate dose (2 cc/rat/day).

\section{Suggestions}

In order to get clinically applicable study results, the same study should be done on healthy humans as volunteers. More study on dose variance should also be done to get the optimal dose of the ethanol extract 

Increase Total Antioxidant Level in Rats with High Glucose Intake

of purple sweet potato tubers in treating hyperglycemic conditions.

\section{Acknowledgement}

The author would like to thanks LITBANG FK UNUD (Research and Development Unit of Medical School, Udayana University) for the financial supports in the period of 2009, so that this research can be done successfully

\section{References}

[1] K. Srinivasan and P. Ramarao, Animal models in type 2 diabetes research: An overview, Indian J Med Res 125 (2007) 451-472.

[2] D. Ghosh and T. Konishi, Anthocyanins and anthocyanin-rich extracts: role in diabetes and eye function, Asia Pac J Clin Nutr. 16 (2) (2007) 200-208.

[3] B. Jayaprakasam, S. K. Vareed, L. K. Olson and M. G. Nair, Insulin secretion by bioactive anthocyanins and anthocyanidins present in fruits, J. Agric. Food Chem 53 (1) (2005) 28-31.

[4] M. E. Lean, M. Noroozi, I. Kelly, J. Burn, D. Talwar, N. Sattar and Crozier, Dietary flavonols protect diabetic human lymphocytes againts oxidative damage to DNA, Diabetes 48 (1) (1999) 176-181.

[5] P. M. Clifton, Effect of grape seed extract and quercetin on cardiovascular and endothelial parameters in high-risk subjects, Journal of Biomedicine and Biotechnology 5 (2004) 272-278.

[6] R. Bitsch, M. Netzel, T. Frank, G. Strass and I. Bitsch, Bioavailability and biokinetics of anthocyanins from red grape juice and red wine, Journal of Biomedicine and Biotechnology 5 (2004) 293-298.

[7] C. Sanchez-Moreno, G. Cao, O. U. Boxin, R. L. Prior, Anthocyanin and proanthocyanidin content in selected white and red wines: oxygen radical absorbance capacity comparison with nontraditional wines obtained from highbush blueberry, J. Agric. Food Chem 51 (2003) 4889-4896.
[8] B. K. Chambers and M. E. Camire, Can Cranberry supplementation benefit adults with type 2 diabetes? Diabetes Care 26 (2003) 2695-2696.

[9] D. N. Suprapta, M. Antara, N. Arya, M. Sudana, A. S. Danuaji and M. Sudarma, Kajian aspek pembibitan, budidaya dan pemanfaatan umbi-umbian sebagai sumber pangan alternative, Laporan Hasil Penelitian, Kerjasama BAPEDA Propinsi Bali dengan Fakultas Pertanian UNUD, 2004.

[10] I. M. Jawi, D. N. Suprapta, S. U. Dwi and I. Wiwiek, Ubi Jalar Ungu Menurunkan Kadar MDA dalam Darah dan Hati Mencit setelah Aktivitas Fisik Maksimal, Jurnal Veteriner Jurnal Kedokteran Hewan Indonesia 9 (2) (2008) 65-72.

[11] D. J. Huang, C. D. Lin, H. J. Chen and Y. H. Lin, Antioxidant and antiproliferative activities of sweet potato (Ipomoea batatas [L.] Lam 'Tainong 57') constituents, Bot. Bull. Acad. Sin. 45 (2004) 179-186.

[12] I. Suda, T. Oki, M. Masuda, M. Kobayashi, Y. Nishiba and S. Furuta, Physiological functionality of purple-fleshed sweet potatoes containing anthocyanins and their utilization in foods, JARQ 37 (3) (2003) 167-173, available online at: http://www.jircas.affrc.go.jp.

[13] X. Han, T. Shen and H. Lou, Dietary polyphenol and their biological significance, Int. J. Mol.Sci. 8 (2007) 950-988.

[14] H. A. H. Kataya and A. E. A. Hamza, Red cabbage (brassica oleracea) ameliorates diabetec nephropathy in rats, Evid Based Complement Alternat Med. 5 (3) (2008) 281-287.

[15] I. Konczak and W. Zhang, Anthocyanins - More than nature's colours, Journal of Biomedicine and Biotechnology 5 (2004) 239-240.

[16] M. Micallef, L. Lexis and P. Lewandowski, Red wine consumption increases antioxidant status and decreases oxidative stres in the circulation of both young and old humans, Nutrition Journal 6 (2007) 27.

[17] R. L. Prior, Fruits and vegetables in the prevention of cellular oxidative damage, American Journal of Clinical Nutrition 78 (3) (2003) 570s-578s. 